\title{
Opportunity for Offshore Wind to Reduce Future Demand for Coal-Fired Power Plants in China with Consequent Savings in Emissions of $\mathrm{CO} 2$
}

\section{Citation}

Lu, Xi, Michael B. McElroy, Xinyu Chen, and Chongqing Kang. 2014. “ Opportunity for Offshore Wind to Reduce Future Demand for Coal-Fired Power Plants in China with Consequent Savings in Emissions of CO 2 ." Environ. Sci. Technol. 48 (24) (December 16): 14764-14771. doi:10.1021/ es503767x.

\section{Published Version}

doi:10.1021/es503767x

\section{Permanent link}

http://nrs.harvard.edu/urn-3:HUL.InstRepos:22560578

\section{Terms of Use}

This article was downloaded from Harvard University's DASH repository, and is made available under the terms and conditions applicable to Open Access Policy Articles, as set forth at http:// nrs.harvard.edu/urn-3:HUL.InstRepos:dash.current.terms-of-use\#OAP

\section{Share Your Story}

The Harvard community has made this article openly available.

Please share how this access benefits you. Submit a story.

Accessibility 


\section{Opportunity for Offshore Wind to Reduce Future Demand for Coal-fired Power Plants in China with Consequent Savings in Emissions of $\mathrm{CO}_{2}$}

\section{Xi Lu, ${ }^{\dagger}$ Michael B. McElroy, ${ }^{\dagger,{ }^{*}}$ Xinyu Chen, ${ }^{\S}$ Chongqing Kang ${ }^{\S}$}

$\uparrow$ School of Engineering and Applied Sciences, Harvard University, Cambridge, MA 02138, United States

\$Department of Earth and Planetary Sciences, Harvard University, Cambridge, MA 02138, United States

$\S$ Department of Electrical Engineering, Tsinghua University, Beijing, 100084, China

Contact Information:

Affiliation: School of Engineering and Applied Sciences and Department of Earth and Planetary Sciences, Harvard University

Address: 100C Peirce Hall, 29 Oxford St., MA 02138

Phone: 617-495-4359

Fax: 617-495-4551

Email: mbm@seas.harvard.edu

\section{Supporting Information}


Although capacity credits for wind power have been embodied in power systems

3 in the U.S. and Europe, the current planning framework for electricity in China continues

4 to treat wind power as a non-dispatchable source with zero contribution to firm capacity.

5 This study adopts a rigorous reliability model for the electric power system evaluating

6 capacity credits that should be recognized for offshore wind resources supplying power

7 demands for Jiangsu, China. Jiangsu is an economic hub located in the Yangtze River

8 delta accounting for $10 \%$ of the total electricity consumed in China. Demand for

9 electricity in Jiangsu is projected to increase from 331 TWh in 2009 to 800 TWh by 2030.

10 Given a wind penetration level of $60 \%$ for the future additional Jiangsu power supply,

11 wind resources distributed along the offshore region of five coastal provinces in China

12 (Shandong, Jiangsu, Shanghai, Zhejiang and Fujian) should merit a capacity credit of

$1312.9 \%$, the fraction of installed wind capacity that should be recognized to displace coal-

14 fired systems without violating the reliability standard. In the high-coal-price scenario,

15 with $60 \%$ wind penetration, reductions in $\mathrm{CO}_{2}$ emissions relative to a business as usual

16 reference could be as large as 200.2 million tons of $\mathrm{CO}_{2}$ or $51.8 \%$ of the potential

17 addition, with a cost for emissions avoided of $\$ 29.0$ per ton.

\section{Introduction}

19 Driven by fast economic growth and the modernization progress over the past 20 decades, demand for electricity in China increased rapidly from $1.32 \mathrm{PWh}$ in 2000 to

$214.69 \mathrm{PWh}$ in 2011 , at an average annual rate of over $12 \%[1,2]$. Coal-fired power

22 systems provided the dominant source for electricity in China. In 2011, approximately

$2382.5 \%$ of China's electricity was generated using coal, with the balance supplied by

24 hydro (14.0\%), nuclear (1.9\%), and wind (1.6\%) [2]. As a result, emissions of $\mathrm{CO}_{2}$ from

25 China's electric power sector were approximately 4.1 billion tons in 2011, accounting for 
$2645 \%$ of the total emissions from the country and $11.5 \%$ of total emissions for the world[3].

27 Demand for electricity in China is projected to increase by $150 \%$ by 2030 relative to

28 2010[4]. If coal-fired power generators continue to dominate China's electricity supply,

29 they may be expected to contribute a significant source of global $\mathrm{CO}_{2}$ emissions into the

30 indefinite future.

The developed coastal regions (including nine provinces and two municipalities),

32 where China's electric load center is concentrated, were responsible for $53.5 \%$ of

33 China's total electricity consumption in 2011[2]. Power generation in coastal provinces of

34 China, as is true for the country at large, is dominated by sources fueled by coal, with

35 percentages ranging from $61 \%$ in Guangxi to as high as $99 \%$ in Shandong in $2011[5]$.

36 To meet the increasing demand for electricity in the coastal region, coal needs to be

37 either transferred from inland provinces in the north and west of China, or imported from

38 Australia and elsewhere[6], reflecting an increasing shortage of domestic coal resources.

39 To harvest the rich onshore wind power, located in the North and West of China,

40 requires significant expansion of the existing transmission grid system on a national

41 scale[7]. As a renewable and convenient energy resource, offshore wind power, we

42 shall argue, can provide an important alternative to coal for supply of electricity to

43 coastal provinces of China with potential for significant savings in $\mathrm{CO}_{2}$ emissions.

44 A number of recent studies indicated that China has abundant offshore wind 45 resources for power generation[8-10]. Lu et al. (2009) using $100 \mathrm{~m}$ wind data derived 46 from the NASA Goddard Earth Observing System Data Assimilation (GEOS-5) found 47 that a network of 3.6-MW turbines deployed in ocean waters with depths $<200$ m within 4850 nautical miles $(92.6 \mathrm{~km})$ of the closest coastline could supply potentially the total 49 current demand for electricity in China[8]. In 2010, an assessment conducted jointly by 50 the Chinese Wind Energy Association (CWEA) and Sun Yat-sen University concluded 
51 that the technical potential for offshore wind energy in China within $100 \mathrm{~km}$ from shore is

52 about 11.6 PWh, more than twice the nationwide electricity demand[9]. Hong and Moller

53 (2011) analyzing the costs of electricity generated from offshore wind in China 54 suggested that offshore wind energy in China could contribute economically to $56 \%$, $5546 \%$ and $42 \%$ of the coastal region's total electricity demands by 2010,2020 and 2030 , 56 respectively[10].

The present study considers Jiangsu province as a case study exploring 58 opportunities for offshore wind power as a source not only of clean electricity but also of 59 firm capacity, providing an important opportunity to reduce requirements for additional 60 coal-fired systems to meet projected demand for electricity in Jiangsu in 2030. 61 Approximately $10 \%$ of the total electricity consumed nationally in China in 2009 was 62 consumed in Jiangsu, an economic hub located in the Yangtze River Delta. In the same 63 year, electric power systems in Jiangsu produced 298 TWh of electricity for 78.7 million 64 consumers $[11,12]$. Coal- fired systems contributed $74.4 \%$ of the total capacity for 65 electricity generation (59.0 GW) in Jiangsu, with the balance supplied by natural gas $66(5.2 \%)$, nuclear power (2.9\%), combined heat and power (CHP, 2.6\%), and pumped 67 hydro (1.6\%). Jiangsu imports electricity from other inland provinces, especially during 68 the peak summer demand period. In 2009, approximately $10 \%$ of the total electricity 69 consumed in Jiangsu (about 32.7 TWh) was imported. Jiangsu was selected for this 70 study for two reasons: first, we have access to electric load data for Jiangsu on an hourly 71 basis, with detailed information on generating units in the existing power system. Second, 72 Jiangsu is leading in exploiting offshore wind resources among other coastal provinces 73 of China. In 2010, some 1.37 GW onshore wind turbines were installed in Jiangsu.

74 Another 3.6 GW of offshore and $1 \mathrm{GW}$ of onshore facilities are planned for deployment 75 during the 12th Five-Year-Plan (FYP) (2011-2015). The official plan sets a target of 7 
76 GW for offshore investments by 2020 with an even larger offshore target of 18 GW over 77 the longer term[13, 14]. The case study for Jiangsu is expected to be of practical 78 importance as an influence on how power system planning should be coordinated with 79 development of offshore wind energy in Jiangsu and other coastal regions in China.

80 Reflecting the intrinsic variability of wind, real time demand for electricity is often 81 poorly correlated with supply[8, 15-17]. Fluctuations in wind power outputs in China are 82 compensated normally by other generation units (mainly coal-fired systems) deployed to 83 balance the instantaneous demand for electricity[16]. The current planning framework for 84 electric power systems in China continues to treat offshore wind sources as non85 dispatchable power. The capacity credit (CC) of wind power, defined by the ratio of firm 86 capacity contributed by wind to its total nameplate capacity, is assigned as zero. In 87 contrast, many power grid regions in the US, such as the PJM Regional Transmission 88 Organization (RTO), New York Independent System Operator (ISO) and New England 89 ISO, have begun to assign CC values to wind facilities[18]. Failure to recognize the 90 potential firm-capacity contribution from wind could lead to unnecessary construction of 91 additional fossil-fuel generating plants in China. A recent study by Lu et al, analyzing the 92 variations of hourly wind power from 12 offshore sites spread along the Chinese 93 coastline, concluded that through an optimal combination of offshore wind facilities 94 distributed over three coastal economic zones (Bohai Bay, the Yangtze River Delta, and 95 the Pearl River Delta), the temporal variability of overall power outputs from offshore 96 wind could be minimized so that as much as $28 \%$ of the total wind capacity could be 97 deployed as base load power replacing the requirements on capacity for coal-fired 98 systems[7]. Their analysis, however, did not consider the costs for integration of offshore 99 wind power into the Chinese grid, nor did it consider the costs for resulting savings in $100 \mathrm{CO}_{2}$ emissions. 
The present analysis is intended to quantify the $\mathrm{CC}$ values that could be

102 assigned to offshore wind based on a reliability model for the electric power system,

103 together with the displacement of electricity generated from coal-fired system that could

104 be realized by wind on an hourly basis. The potential electricity generation from offshore

105 wind on an annual basis is assumed to vary from $0 \%$ to $60 \%$ in terms of its energy

106 values relative to the additional system-wide load demand for Jiangsu between 2009

107 and 2030. The specific percentage value is referred to hereafter as the penetration level

108 for wind power. Costs for integrating offshore wind power and associated costs for

109 reductions of $\mathrm{CO}_{2}$ will be quantified for each wind penetration level. As a step forward

110 from the earlier studies[7, 17], this paper investigates also the implications for reductions

111 in $\mathrm{CO}_{2}$ emissions and associated costs for the future integration of geographically

112 dispersed offshore wind resources into a specific coastal electric power system. The

113 study considers the potential supply of electricity from offshore wind resources

114 distributed over coastal regions for both the study province (Jiangsu/Shanghai) and for

115 neighboring provinces (Shandong, Zhejiang and Fujian).

116 Data and Methods

117 The present analysis adopts a reliability model formulation for electric power

118 system to evaluate the multifaceted implications pertaining to the future incorporation of

119 offshore wind into Jiangsu's power system by 2030. Results will be compared with a

120 business as usual (BAU) reference which assumes that all of the increase in demand for

121 electricity between 2009 and 2030 will be met solely by new coal-fired systems with zero

122 contribution from offshore wind. The electricity supply for the additional load in 2030

123 relative to 2009 in the alternative scenarios will involve a combination of coal-fired

124 systems and offshore wind facilities, allowing the energy penetration levels for offshore

125 wind to vary from 0 to $60 \%$. The power system is required to maintain the same degree

126 of reliability at each wind penetration level as with the BAU reference. We are interested 
127 particularly in understanding the capacity values (or capacity credits) that could result 128 from offshore wind power, as well as how electricity generated using coal could be 129 displaced by offshore sources. Building on this, the costs for integrating offshore wind 130 power and associated costs for savings in $\mathrm{CO}_{2}$ emissions will be quantified as a function 131 of wind penetration level.

Wind data used for this analysis were derived for 2009 from the Goddard Earth

133 Observing System Data Assimilation System (GEOS-5 DAS) by the U.S. National 134 Aeronautics and Space Administration (NASA)[19]. The data include records of wind 135 speeds on an hourly basis with a spatial resolution of 0.33 degree longitude by 0.25 136 degree latitude (approximately equivalent to $33 \mathrm{~km} \times 25 \mathrm{~km}$ at mid-latitude). Wind 137 speeds at $100 \mathrm{~m}$ elevation are extrapolated from winds at $50 \mathrm{~m}$ and $10 \mathrm{~m}$ using a 138 vertical power law profile [7, 20]. The hourly power outputs from offshore wind were 139 computed using the power curve appropriate for GE 3.6 MW wind turbines[21].

140 Two different regions will be considered with respect to the potential electricity 141 supply from offshore wind resources: Region 1, wind facilities located in the shallow sea 142 regions of Jiangsu and Shanghai only; Region 2, an equal combination of sources from 143 Jiangsu/Shanghai, Zhejiang, Shandong and Fujian. The latter case was selected to take 144 advantage of the smoothing effect on the variation of offshore wind power that can be 145 realized through a combination of power sources from geographically distributed 146 offshore regions [7]. We focus attention on offshore wind resources within shallow, 147 near-shore areas and intertidal zones (specifically, imposing constraints on both water 148 depth, $\leq 30 \mathrm{~m}$, and proximity to the closest shoreline, $\leq 80 \mathrm{~km}$ ), where offshore wind has 149 been identified as the top priority for exploitation in China. Locations for the offshore 150 wind resources for the two cases considered are indicated in Figure 1. 


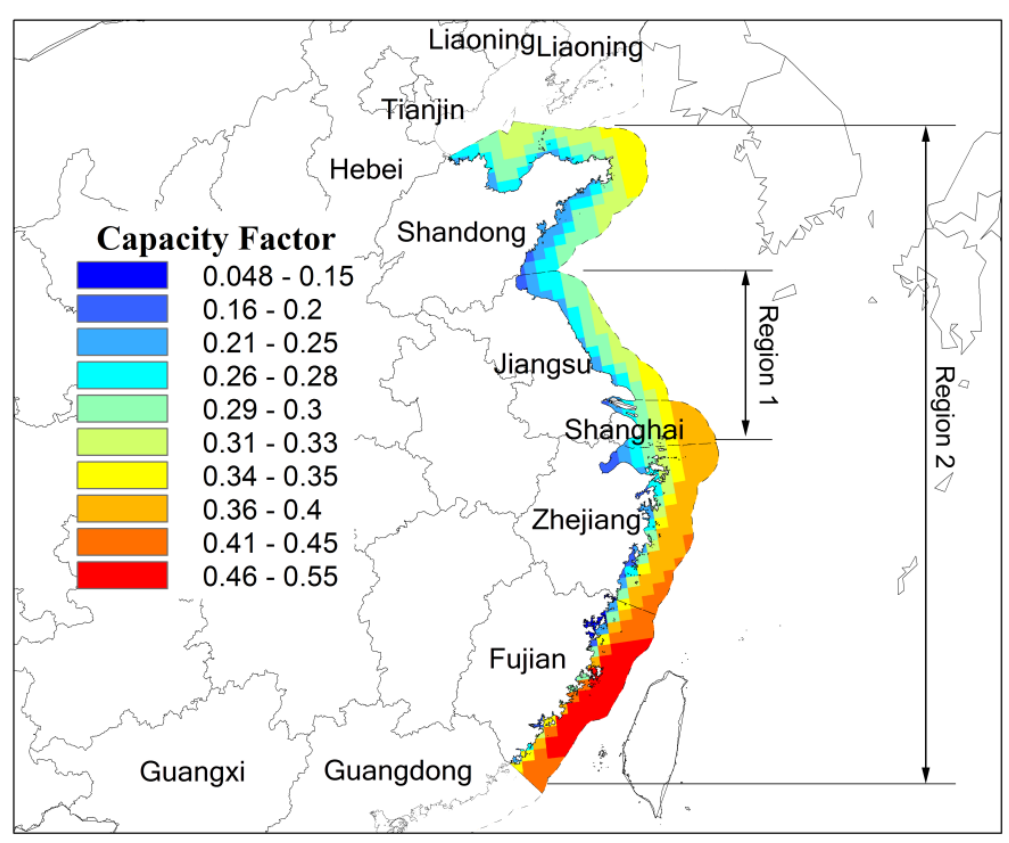

Figure 1. Wind resources for the two offshore regions discussed in the text. Distribution of annual average capacity factors (CFs) evaluated for deployment of a network of GE $3.6 \mathrm{MW}$ wind turbines within a distance of $80 \mathrm{~km}$ from the shoreline.

Future demand for electricity in Jiangsu province is projected to more than double by 2030 relative to 2009 , increasing to 800 TWh in 2030 from 331 TWh in 2009 , under the assumption of an annual growth rate of approximately $6.4 \%$ between 2009 and $2020,2 \%$ between 2020 and 2030[4]. The variation of the load demand with time in 2030 is assumed to vary in a temporal fashion identical to the pattern that pertained in 2009. A comparison of hourly power outputs from offshore wind for the two cases described with the hourly additional electric load in 2030 relative 2009 is plotted in Figure 2 for the first weeks of February, May, August and November respectively.

The present study adopts the Loss of Load Probability (LOLP) approach as a measure of the reliability of the Jiangsu power system. This is defined in terms of the number of hours that load is permitted to exceed the available generation capacity over the course of a year. The LOLP for a power system at a given penetration level of wind varies as a function of a number of variables including not only hourly loads and outputs of wind power, but also generation capacity, minimum power output, and the forced 
outage rate (FOR) for each generating unit in the system[18]. The detailed method for

170 calculating LOLP is described in the Supporting Information (SI). The regulatory

171 paradigm for the power system in China requires a maximum limit for LOLP of 12 hours

172 per year [22]. This criterion for LOLP was adopted in the present study to evaluate the

173 additional capacities of coal-fired systems that would be required in the BAU reference

174 scenario and in all of the alternative scenarios.

175 To maintain the LOLP below its maximum allowable limit in a power system, the 176 total installed capacity for power generation must exceed the maximum load by a 177 specific margin since individual power generating units can experience mechanical or 178 electrical failures requiring them to be taken out of service (the probability of this 179 situation is measured by the FOR). Given the additional demand for electricity in 2030, 180 the LOLP calculated for the electricity generating capacity for Jiangsu existing in 2009 181 would necessarily violate the reliability standard (i.e. 12 hours per year) where this 182 system required satisfying demand anticipated for 2030. In the BAU reference, new coal183 fired systems are needed to ensure that the power system should meet the LOLP 184 standard in 2030. Each coal-fired unit is assumed to have a capacity of $600 \mathrm{MW}$ with a 185 FOR of $8.5 \%[23,24]$. Adding one new coal power plant will increase the capacity 186 adequacy of the system, decreasing thus the value of LOLP. Continuing an iterative 187 process with sequential addition of coal-fired units, the total capacities required for new 188 coal-fired systems can be computed to define the point at which the LOLP of the system 189 falls below the maximum limit.

190 The method for calculating the additional coal capacities required in the BAU 191 reference was applied also to the alternative scenarios reflecting different levels of 192 electricity derived from offshore wind. In this case, the expansion of the coal fired system 193 aims not at meeting additional load in the BAU reference but rather at meeting the net 
194 additional load after deduction of the supply from offshore wind. The firm capacity 195 contributed from offshore wind power in each alternative scenario can be estimated 196 based on the corresponding savings in new coal capacities that would be required 197 otherwise in the BAU reference. The values of capacity credits (CC) assigned to offshore 198 wind facilities reflect the fractions of installed wind capacity by which the capacities for 199 coal-fired system can be displaced without compromising the LOLP constraint [25, 26].

200 The CC values of wind power can be expressed as follows:

$$
\text { Capacity Credit }=\frac{\text { Displacement of Thermal Capacities }}{\text { Total Wind Capacities }} \times 100 \% \text {, }
$$

On occasions when the penetration level of offshore wind power is high, the 203 power system may not have flexibility adequate to fully accommodate the potential 204 source from wind. This results in an inevitable curtailment of wind power. In this study, 205 we estimate the curtailments implied for hourly power output of offshore wind systems, 206 considering not only the hourly load and wind power outputs, but also the minimum 207 power outputs required for both existing and newly built coal-fired systems. Coal-fired 208 units in China typically must be operated to maintain power outputs at a level greater 209 than $50 \%$ of rated full capacity. Otherwise, plants would be forced to shut down during 210 off-peak periods and to restart in peaking hours, an extremely costly and inefficient 211 option. It takes hours for a coal power plant to fire up from a cold start and return to its 212 normal operational condition. In this analysis, coal-fired systems are assumed to stay 213 online during the night when load is low so that they can ramp up during daytime to meet 214 load as it peaks. Winds tend to be strong during the night, and part of electricity supply 215 from wind power must be curtailed for most cases under such circumstances. The 216 detailed method for estimating curtailments of offshore wind power is described in the SI. 
Costs for future generation of electricity using coal-fired systems in Jiangsu 218 depend on a combination of capital investment, Operation and Maintenance (O\&M) 219 costs, fuel consumption, and prices for coal. The economic parameters appropriate for 220 coal power plants for both current (Cost A) and future (Cost B) cost scenarios are 221 summarized in Table $1[27,28]$. We assume that the future capital costs and efficiency of 222 coal fired systems are the same in the Cost B scenario as with the Cost A option, 223 assuming that additional pollution control systems in the new power plants that will be 224 required to operate in a more restricted future environmental regulatory environment in 225 China will offset the potential decrease in capital costs and improvement in efficiency 226 resulting from progress reflected in the learning curve. An efficiency of $40 \%$ was 227 assumed for new coal-fired systems [29]. The present study is intended to investigate 228 carbon emissions associated with electricity production. $\mathrm{CO}_{2}$ emission with per $\mathrm{kWh}$ of 229 electricity generation using coal was estimated then at $0.83 \mathrm{~kg}[29,30]$. Zero $\mathrm{CO}_{2}$ 230 emissions were assigned for wind-generated electricity. The average price of $\$ 96.5$ per 231 ton of standard coal (\$3.5/MMBTU) was selected for the Cost A scenario based on 232 prices that prevailed at all major coal exchange hubs in China in September 2012[31] 233 (nearly twice the concurrent price for coal in the US). The price for coal in China is 234 expected to increase by $45 \%$ in the Cost B scenario relative to Cost $A$ [32], reflecting the 235 increasing future demand for coal and the higher costs for mining in suboptimal locations.

236 There are a number of factors impacting the costs for electricity generated from 237 offshore wind, including the quality of wind resources, wind turbine costs, construction 238 environments (such as distances from shorelines and depths of ocean water) and the 239 cost for managing and maintaining operations, all of which are subject to uncertainty[10, 240 33]. In 2010, four offshore wind farms successfully completed the first concession 241 bidding process for offshore demonstration projects in China, with a range of bidding 
242 prices from $9.7 \mathrm{c} / \mathrm{kWh}$ to $11.6 \mathrm{c} / \mathrm{kWh}$ in 2013 US dollars[13, 14]. Wind turbine costs are

243 expected to decrease by $15 \%$ to $37 \%$ in real prices by 2030 reflecting improvements in

244 technology [33]. O\&M costs are expected to decrease also benefiting not only from

245 lessons learned from offshore wind farms in China but also from experience in the rest of

246 the world. The analysis assumes that capital costs are $\$ 2650 / \mathrm{kW}$ for the Cost $A$

247 scenario, $\$ 2000 / \mathrm{kW}$ for the Cost B option, with annual O\&M costs estimated at $1.5 \%$ of

248 the upfront capital cost [34].

249 Table 1 Cost parameters for the future coal fired systems in Jiangsu Province and for 250 the offshore wind facilities in both regions discussed in the text (in 2013 US dollars)

\begin{tabular}{|l|l|l|l|}
\hline \multirow{3}{*}{$\begin{array}{l}\text { Coal-fired } \\
\text { systems }\end{array}$} & Items & Cost A & Cost B \\
\cline { 2 - 4 } & $\begin{array}{l}\text { Vapital cost }(\$ / \mathrm{kW}) \\
\text { cost(c/kWh) }\end{array}$ & 650 & 650 \\
\cline { 2 - 4 } & Fixed O\&M cost (\$/kW) & 0.46 & 0.46 \\
\cline { 2 - 4 } & Fuel cost (\$/MMTU) & 32 & 32 \\
\cline { 2 - 4 } & Efficiency (\%) & $40 \%$ & 5 \\
\cline { 2 - 4 } & Lifetime (years) & 35 & $30 \%$ \\
\hline \multirow{3}{*}{ Offshore Wacilities } & Wind & 2650 & 30 \\
\cline { 2 - 4 } & O\&M cost (\$/kW) & 40 & 2000 \\
\cline { 2 - 4 } & Lifetime (years) & 20 & 30 \\
\hline
\end{tabular}

251

\section{Results}

253 As illustrated in Figure 3, CCs were evaluated for potential offshore wind facilities

254 in Regions 1 and 2 (defined in Section 2) as a function of penetration levels of wind 255 power relative to the additional load demand projected for Jiangsu in 2030 . When the 256 contribution from wind power is as low as $1 \%$, CC values for wind power amount to $25732.2 \%$ in Region 1, 29.6\% in Region 2, approximately equal to the average realizable 258 capacity factors (CFs) respectively of $31.1 \%$ and $34.3 \%$. The values of CC in both cases 
decrease with increasing penetration of wind, approaching constant values at large

260 penetrations. At a wind penetration level of $35 \%$, the CC values are $12.3 \%$ and $15.9 \%$

261 respectively for the potential offshore wind facilities envisaged in Regions 1 and 2 . To

262 put this into context, new wind projects in the power grid overseen by the New York ISO

263 in the U.S. are assigned a summer CC of $10 \%$ and a winter CC of $30 \%$ [18].

The advantage for wind resources in Region 2 as compared to Region 1 in terms

265 of potential CC values is notable under circumstances where the wind penetration levels

266 are at or above $20 \%$. At a penetration level of $60 \%$, the CC values for wind power are

$2679.1 \%$ in Region 1, $12.9 \%$ in Region 2. This implies that for large wind penetrations,

268 approximately $12.9 \%$ of the total installed capacities for offshore wind facilities

269 envisaged in Region 2 can be used to displace coal-fired systems. Deploying the same

270 amount of wind, the offshore wind facilities in Region 2 would replace an additional

$27142.9 \%$ of coal-fired capacities as compared to that projected for Region 1. The additional

272 benefits projected at high wind levels for Region 2 relate to the fact that wind resources

273 in this case are harvested from a wide coastal region spreading from north to south

274 (Figure 1), influenced by distinct weather systems[7, 35]. As a result, low power outputs

275 from one offshore wind facility are statistically compensated by high outputs from others

276 within the same region, increasing the minimum production realizable at times of peak 277 load.

278 It is interesting to note that the $\mathrm{CC}$ values realized for wind resources in Region 1

279 are higher than for Region 2 at wind penetration levels of $5 \%$ or less. This arises from

280 the fact that the probability that hourly outputs of wind power in Region 1 are either high

281 or low tends to be greater as compared with the extremes observed for Region 2 (see

282 the SI). With a small fraction of wind power in the electric grid system, the often-

283 occurring low power outputs for wind systems in Region 1 can be compensated by non- 
284 wind components of the power system, while the more frequent high power outputs 285 contribute to provide higher potential value for CC. The CC values for individual seasons 286 are presented in the SI.

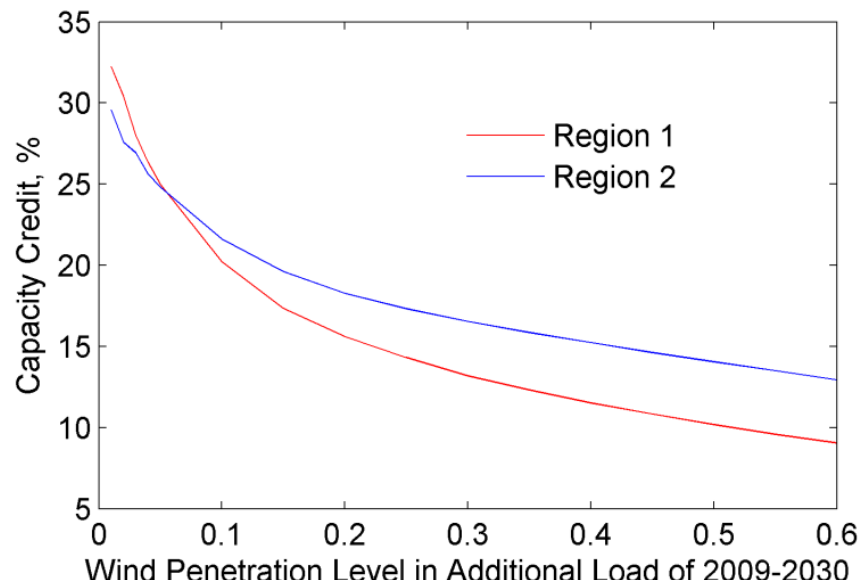

Figure 3. Capacity credits of offshore wind power as a function of its penetration level to additional load of Jiangsu power system in 2030 relative to 2009 for two regions discussed in the text

Figure 4 displays the different electricity mixes projected to meet the additional load demand for Jiangsu in 2030. In the BAU reference, the additional load (470 TWh) in 2030 would be met by coal-fired systems, implying an increase in annual $\mathrm{CO}_{2}$ emissions of 419 million tons. At a wind penetration level of $60 \%$, offshore wind power from Regions 1 and 2 could supply respectively $45.3 \%$ and $51.7 \%$ of the additional load. The corresponding savings in emissions of $\mathrm{CO}_{2}$ are 175.2 million tons for Region 1 and 200.2 million tons for Region 2, accounting respectively for $32.7 \%$ and $37.6 \%$ of total $\mathrm{CO}_{2}$ emissions from the entire energy economy of Jiangsu in 2009[30].

Curtailments of wind power were estimated for different wind penetration levels. When the contribution from wind is low, the non-wind components of the power system required to cope with variations in demand for electricity are capable of compensating for slightly greater variations in the residual demand for electricity or net load (defined as the instantaneous system load minus wind power). Under these circumstances, the amount 
304 of electricity generated from coal that displaced by offshore wind exhibits a linear 305 relationship as a function of wind penetration levels [36] (Figure 4). With additional wind, 306 the non-wind components of the power system experience increasingly frequent 307 suboptimal operation requiring steeper ramping up or down. Curtailments begin to occur 308 when the wind penetration level reaches a critical value, the curtailment point. As

309 illustrated in Figure 4, the curtailment point is reached at a wind penetration level of $10 \%$

310 for the offshore wind facilities envisaged in Region 1, shifting to the a penetration level of $311 \quad 15 \%$ for Region 2.

312 In the curtailment regime, the reductions in electricity produced using coal vary as a 313 sub-linear function of wind penetration levels. At high penetrations, there are notable 314 advantages for the dispersed offshore wind power available in Region 2 as compared 315 with Region 1. For example, at a wind penetration level of $60 \%$, as much as $68.6 \mathrm{TWh}$ 316 electricity produced from wind would be curtailed in Region 1, approximately $78.4 \%$ 317 higher than curtailment estimated for Region 2. The difference is attributed primarily to 318 the fact that wind resources are influenced by distinct weather systems in different 319 locations in Region 2, canceling out to a significant extent variability from individual 320 sources [7]. The resulting overall power output is smoother on an hourly basis in Region 3212 as compared to Region 1 (see Figure 1). At a wind penetration of $60 \%$, the percentage 322 of curtailment evaluated for Region 2 is approximately $13.7 \%$, significantly lower than the 323 value estimated for Region $1,24.5 \%$. To put this in context, the curtailment ratio was 324 close to $16 \%$ for existing onshore wind farms in China in 2011 , resulting in a financial 325 loss of as much as one billion US dollars [37], while wind-generated electricity accounted 326 of $5.2 \%$ of the incremental load between 2007 and 2011. 

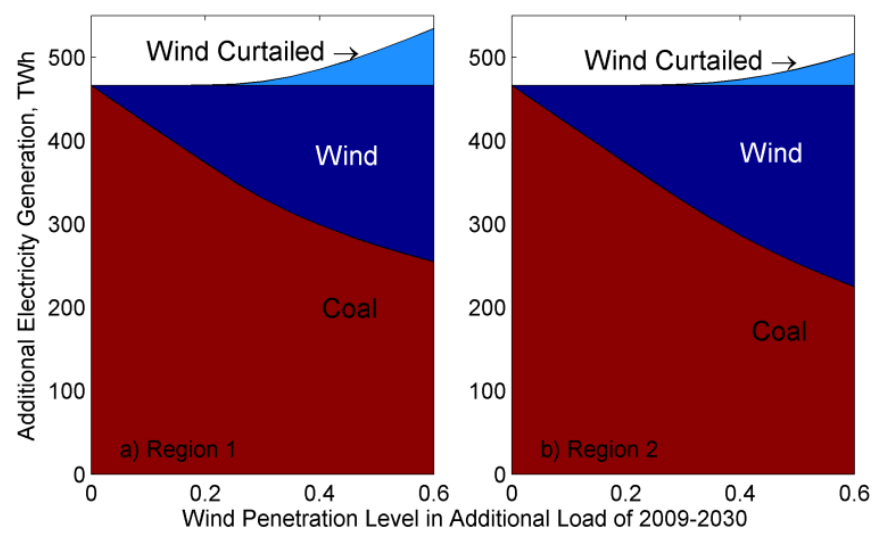

Wind Penetration Level in Additional Load of 2009-2030

Figure 4. Mix of electricity supply for additional load in Jiangsu province between 2009 and 2030 for wind penetration levels varying from $0 \%$ to $60 \%$ : a) for wind resources in Region 1 and b) for Region 2.

The breakdown of costs associated with increased electricity generation for the different penetration levels of offshore wind power is illustrated in Figure 5. Costs for

333 upfront investment in both coal-fired systems and offshore wind power facilities were

334 amortized for each year discounted to present values over their lifetimes, assuming a 335 discount rate of $7 \%[34]$. The overall costs for the non-wind BAU references are $\$ 20.3$ 336 billion and $\$ 26.3$ billion for the Cost $A$ and Cost B scenarios respectively, the difference 337 reflecting the higher prices for coal assumed in the latter case. With increasing 338 penetrations of electricity from offshore wind, greater contributions of power from coal 339 were replaced by wind. The amortized annual fuel costs for coal-fired systems decline 340 accordingly. There is also a slight downward trend in the upfront investment costs for 341 coal-fired systems reflecting the greater firm capacity, a product of $\mathrm{CC}$ values and the 342 corresponding total wind capacities contributed by the offshore wind installations. These 343 savings are more than offset by the costs for upfront investment and O\&M needed to 344 develop the offshore wind facilities, resulting in a net increase in overall costs for both 345 regions. The slopes for the Cost A scenario are steeper than for the corresponding 346 cases with the Cost B option reflecting the lower investment costs for offshore wind 347 systems assumed in the latter case. 


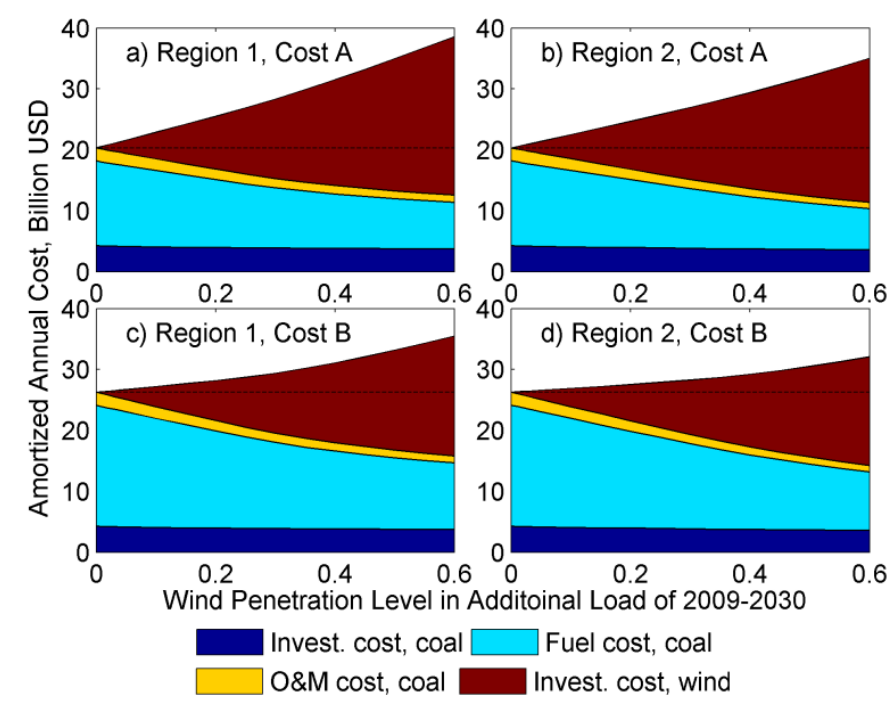

Figure 5. Costs of electricity to meet the additional load of Jiangsu from 2009 to 2030 for penetration levels of wind power from $0 \%$ to $60 \%$ : a) for Region 1, Cost A scenario; b) for Region 2, Cost A scenario; $c$ ) for Region 1, Cost B scenario and d) for Region 2, Cost B scenario.

In both cost scenarios, wind resources in Region 2 are superior to those in Region 1 in terms of costs for the additional electricity supply, especially under high penetration levels. Taking the Cost B scenario as an example, the total costs for Region 2 are $\$ 3.2$ billion lower than the costs for Region 1 at a wind penetration level of $60 \%$. A number of factors are responsible for the cost differences between Region 1 and Region 2. The average CFs for potential offshore wind facilities are estimated at $31.1 \%$ for Region 1 and $34.3 \%$ for Region 2, resulting in lower requirements for the capacities of total wind installations in Region 2 compared to Region 1. For a wind penetration level of $60 \%$, the required capacities for wind power are $103.3 \mathrm{GW}$ and $93.8 \mathrm{GW}$ respectively for Regions 1 and 2. Additionally, greater savings in capacities and fuel consumption for the coal-fired systems relative to the BAU reference are realized by tapping wind resources in Region 2 as compared to Region 1, reflecting the higher firm wind capacities and lower curtailments of wind-generated electricity realized in the former case as compared to latter. 
At wind penetration levels of $10 \%$ or lower, wind-power installations for Region 1 provide more firm capacity as compared with Region 2 . The total wind capacity required 369 for Region 1 is higher than for Region 2 at the same penetration level. Combined with 370 the relatively high CC values with the wind resources in Region 1 at low penetration 371 levels (see Figure 3), these factors contribute to greater displacement of coal systems in

372 Region 1. When penetrations for wind power reach $10 \%$ or higher, the advantage of 373 greater CC values realized by wind power in Region 2 more than offsets the impact of 374 the larger wind capacities available in Region 1, resulting in enhanced savings in coal375 fired power capacities in the former case. As a consequence, in both the Cost $A$ and 376 Cost B scenarios, there is a flipping point at wind penetration level of $10 \%$ for the relative 377 overall costs for coal-fired systems between Region 1 and Region 2.

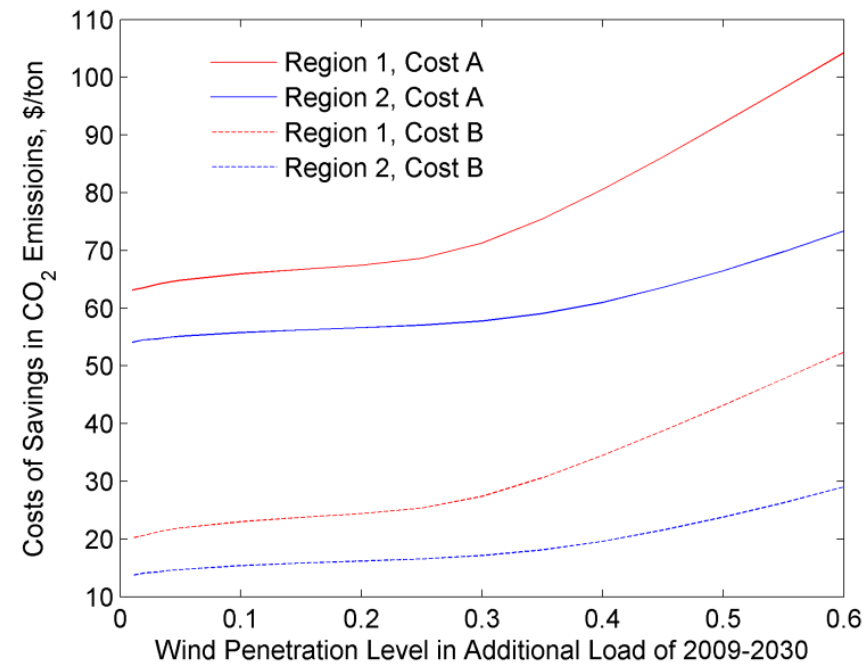

Figure 6. Reduction costs for $\mathrm{CO}_{2}$ emissions associated with additional electricity supply in 2030 of Jiangsu province as a function of penetration levels of offshore wind power

Costs for reduction of $\mathrm{CO}_{2}$ emissions associated with integrating offshore wind power into the additional 2030 load for Jiangsu are illustrated in Figure 6 . There are clear transition zones in the trends of costs for reductions of $\mathrm{CO}_{2}$ emissions: at a wind penetration level of $25 \%$ for Region 1 , at $35 \%$ for Region 2 . The costs for $\mathrm{CO}_{2}$ avoided 
386 tapping wind resources for the two regions tend to increase slowly in advance of these 387 transition zones, exhibiting rapid subsequent growth. At low penetrations of wind, most 388 of the electricity generated from offshore resources is readily accommodated by the 389 power system. At the same time, the firm capacities provided by these wind systems 390 serve to decrease requirements for investments in new coal systems. The slow growth 391 trends for abatement costs of $\mathrm{CO}_{2}$ before the transition zones reflect the decreasing 392 values of CC attributed to the offshore wind facilities as increasing supplies of wind 393 power are accommodated. For wind penetration levels beyond the transition zones, a 394 significant portion of offshore wind power must be curtailed, and is thus unavailable to 395 displace electricity from coal and to contribute to reductions in the emissions of $\mathrm{CO}_{2}$.

396 The marginal reduction costs for emissions of $\mathrm{CO}_{2}$ attributed to the curtailment of wind 397 power are summarized in the SI.

398 For the same wind regions, the reduction costs are significantly higher in the Cost $\mathrm{A}$ 399 scenario as compared to Cost B. Taking wind resources from Region 2 as an example, 400 the costs for savings in $\mathrm{CO}_{2}$ emissions in the Cost $\mathrm{B}$ scenario vary from $\$ 13.7$ per ton to $401 \$ 29.0$ per ton as wind penetration levels increase from $1 \%$ to $60 \%$, while the costs in the 402 Cost A scenario increase from $\$ 20.2$ per ton to $\$ 52.4$ per ton over the same range of 403 wind penetrations. The wide difference in costs for avoided $\mathrm{CO}_{2}$ between the two 404 scenarios reflects mainly the differences in investment costs assumed for offshore wind 405 facilities, together with the different prices assumed for coal.

406 Under the same cost scenario, a number of factors associated with the offshore 407 wind resources contribute to the differences in costs for avoided $\mathrm{CO}_{2}$ between the two 408 regions, namely the CF and CC values, and the curtailment ratios for wind power. The 409 gap in reduction costs for $\mathrm{CO}_{2}$ between Region 1 and Region 2 is relatively narrow in 410 advance of the transition zones, diverging subsequently. In the Cost B scenario, the 
411 costs for reduction of $\mathrm{CO}_{2}$ emissions resulting from exploitation of wind resources in

412 Region 2 are lower than for Region 1 by $\$ 6.5$ per ton at a wind penetration level of $5 \%$,

$413 \$ 10.3$ per ton at $30 \%$, and up to $\$ 23.4$ per ton at $60 \%$. The cost-effectiveness for saving

$414 \mathrm{CO}_{2}$ emissions in Region 2 is particularly prominent at wind penetration levels beyond

415 the transition zones, reflecting primarily the relatively smaller curtailment and higher CC

416 values realized by tapping wind resources in Region 2 as compared with the less

417 favorable resources available in Region 1.

418 Should the wind power contemplated in Region 2 be deployed in the Cost B 419 scenario, with $30 \%$ wind penetration, reductions in $\mathrm{CO}_{2}$ relative to the $\mathrm{BAU}$ reference 420 could be as large as 115.0 million tons of $\mathrm{CO}_{2}$ or $29.6 \%$ at a cost for abatement of as low 421 as $\$ 17.1$ per ton. Even greater reductions, 200.3 million tons of $\mathrm{CO}_{2}$ or $51.8 \%$, could be 422 realized at a wind penetration level of $60 \%$ but at a higher cost, $\$ 29.0$ per ton. The 423 results suggest that interlinked offshore wind facilities from five Jiangsu-centered coastal 424 provinces in China could provide a means to abate $\mathrm{CO}_{2}$ emissions that would be 425 significantly more cost-effective as compared for example with options for carbon 426 capture and sequestrations (CCS), costs for which could range as high as \$260 per 427 ton[38].

428 It should be pointed out that the existing paradigm for planning the future power 429 system in China assigns zero CC value to wind facilities, which leads to high estimates 430 of costs for abatement of $\mathrm{CO}_{2}$ emissions using offshore wind power. If the potential for 431 firm capacities contributed by offshore wind facilities is discounted, for example for 432 Region 2 in the Cost $\mathrm{B}$ scenario, the costs for avoided $\mathrm{CO}_{2}$ using offshore wind would be 433 raised by $\$ 5.24$ per ton at a penetration level $5 \%$ decreasing to $\$ 3.17$ per ton at a 434 penetration level of $60 \%$ (see the $\mathrm{SI}$ ). 


\section{Discussion}

436 The present analysis adopted a rigorous LOLP-based approach to evaluate the 437 capacity credits that could be realized by recognizing the potential value of offshore wind 438 resources in China. The methodology considered hourly wind power outputs potentially 439 available in two different offshore regions, with detailed information on both existing and 440 new power generating units, and hourly load data for the future electric power system for 441 Jiangsu. The results demonstrate that offshore wind power could provide significant firm 442 capacities that could be used to reduce the need for new coal-fired systems. With wind 443 penetrations as large as $60 \%$, firm capacities for wind power could be as high as $9.3 \mathrm{GW}$ 444 for Region 1, 12.6 GW for Region 2.

445 Benefits of combining offshore wind resources from an extended offshore region 446 were investigated by comparing the results for Regions 1 and 2 with respect to both the 447 CC values potentially available and implied curtailments of wind-generated electricity. 448 Results for Region 2 suggest higher CC values and lower curtailment ratios especially 449 for high wind penetrations in comparison with Region 1, leading to an enhanced 450 capability of offshore wind facilities for Region 2 reducing requirements for both new 451 capacities and fuel demand for coal-fired systems. The lowest costs for reductions in $452 \mathrm{CO}_{2}$ emissions were identified for Region 2 under the Cost B scenario. They range from 453 as low as $\$ 13.7$ per ton of $\mathrm{CO}_{2}$ at a wind penetration level of $1 \%$ to $\$ 29.0$ per ton of $\mathrm{CO}_{2}$ 454 at a penetration level of $60 \%$.

The offshore wind resources envisaged for Region 2 were distributed along the 456 coastline feeding into two weakly connected power grid regions: the North China Power 457 Grid including Shandong, and the East China grid covering the other provinces (Jiangsu, 458 Zhejiang and Fujian) and the municipality (Shanghai) in Region 2. To realize the 459 advantage of high CC values and low curtailment of wind power contemplated in Region 
2, it will be necessary to strengthen the connection between those two. Despite high

461 capital costs, investments to upgrade the backbone transmission network will be needed 462 eventually to accommodate anticipated future growth in demand for electricity whether this 463 power is supplied by offshore wind or by other possible sources (nuclear for example). China's

464 2011-2015 12th Five-Year Plan proposes construction of a super grid system using ultra 465 high voltage alternating current $(A C)$ lines integrating the North China, Central China, 466 and Eastern China regional grids[33, 39]. The strategy for offshore developments will 467 involve most likely linking the offshore wind facilities individually to local on-shore 468 transmission systems taking advantage of the anticipated increase in the 469 interconnectivity of the land-based regional grid systems.

The price of coal was assumed to increase by $45 \%$ in 2030 under the Cost B 471 scenario relatively to the Cost $\mathrm{A}$ situation, contributing to an important difference in costs 472 between these scenarios in terms of avoided $\mathrm{CO}_{2}$ emissions for both Regions 1 and 2.

473 China switched from the condition as a net exporter to a net importer of coal in 2009[6].

474 To an increasing extent, future supplies of coal are expected to depend on imports, 475 driving up prices. According to the annual statistical report by BP [40], the ratio of 476 reserves to production for China's coal is approximately 33 years. If production of coal in 477 China were to grow at an annual rate of $3.5 \%$ as projected by BP for the $2010-2020$ time 478 periods [40], the analysis would suggest that China could run out of domestic supplies of 479 coal by as early as 2032. Offshore wind resources - domestically available in close 480 proximity to the developed coastal regions - provide not only an economically viable 481 means to reduce consumption of coal with consequent reduction in emissions of $\mathrm{CO}_{2}$, 482 they can make an important contribution also to the challenge China faces in terms of its 483 national energy security. 
research was supported by the National Foundation, NSF-AGS-1019134, and by the

Full description of the methodology to estimate the LOLP, the requirements on reserves, and curtailment of wind power, as well as the results for capacity credits of wind power on a seasonal basis, the generation duration curve of wind power, reduction of $\mathrm{CO}_{2}$ emissions due to the capacity credit of wind power, and the additional reduction costs for emissions of $\mathrm{CO}_{2}$ caused by wind curtailments. This information is available free of charge via the Internet at http://pubs.acs.org/ . Commission: Beijing, May, 2012; p 111.

503 3. Boden, T. A.; Andres, R. J.; Marland, G. Preliminary 2011 and 2012 Global \&

504 National Estimates; Carbon Dioxide Information Analysis Center: Oak Ridge, Tennessee 505 2013; p 4.

506 4. National Power Planning Research Center, China's Mid-term and Long-term Development Plan for Supply and Demand for Electricity. China Energy News Feburary 2013, 2013, p 4.

5. Ma, J.; Zhang, W.; Luo, L.; Xu, Y.; Xie, H.; Xu, X.; Li, Q.; Zheng, J.; Sheng, L., China Energy Statistical Yearbook 2011. China Statistics Press: Beijing, 2011; p 1057. 6. Morse, R. K.; He, G. The World's Greatest Coal Arbitrage: China's Coal Import Behavior and Implications for the Global Coal Market; Working Paper \#94; Freeman Spogli Institude for International Studies: Stanford, CA, August 2010, 2010; p 25. 7. Lu, X.; McElroy, M. B.; Nielsen, C. P.; Chen, X.; Huang, J., Optimal integration of offshore wind power for a steadier, environmentally friendlier, supply of electricity in China. Energy Policy 2013, 62, (2013), 131-138.

8. Lu, X.; McElroy, M. B.; Kiviluoma, J., Global potential for wind-generated electricity. Proc. Natl. Acad. Sci. USA 2009, 106, (27), 10933-10938.

9. Xiao, Z.; Zhu, R.; Song, L.; Cheng, X.; He, X.; Jiang, Y.; Lin, S.; Liu, Y.; Shen, Y.; Tao, S.; Wang, X.; Wang, Y.; Xu, J.; Yuan, C.; Zhang, D.; Zhang, X.; Zhang, Y.; Zhao, D.; Zhou, R.; Zhu, J., Assessment of Wind Resources in China 2009. 1 ed.; China Meteorological Press: Beijing, China, 2010; p 141. 
10. Hong, L. X.; Moller, B., Offshore wind energy potential in China: Under technical,

spatial and economic constraints. Energy 2011, 36, (7), 4482-4491.

11. NBS, Tablulation on the 2010 Population Census of People's Republic of China. China Statistics Press: Beijing, 2012.

12. Electric Power Statistical Year Book Editorial Board, Electric Power Statistical Year Book 2011. China Electric Power Press: Beijing, 2012; p 818.

13. Li, J.; Cai, F.; Qiao, L.; Xie, H.; Gao, H.; Yang, X.; Tang, W.; Wang, W.; Li, X., China Wind Energy Outlook 2012. Chinese Renewable Energy Industry Association: Beijing, China, 2013.

14. Li, J.; Shi, P.; Gao, H. China Wind Power Outlook 2010; 978-7-5443-2968-2; Chinese Renewable Energy Industries Association: Beijing, 2011; p 108.

15. Lu, X.; McElroy, M. B.; Sluzas, N. A., Costs for Integrating Wind into the Future ERCOT System with Related Costs for Savings in $\mathrm{CO}_{2}$ Emissions. Environ. Sci. Technol. 2011, 45, (7), 3160-3166.

16. Yu, D. Y.; Liang, J.; Han, X. S.; Zhao, J. G., Profiling the regional wind power fluctuation in China. Energy Policy 2011, 39, (1), 299-306.

17. Kempton, W.; Pimenta, F. M.; Veron, D. E.; Colle, B. A., Electric power from offshore wind via synoptic-scale interconnection. Proc. Natl. Acad. Sci. USA 2010, 107, (16), 7240-7245.

18. Milligan, M.; Porter, K. Determining the Capacity Value of Wind: An Updated Survey of Methods and Implementation; U.S. National Renewable Energy Laboratory: Golden, CO, June, 2008; p 30.

19. Rienecker, M. M.; Suarez, M. J.; Todling, R.; Bacmeister, J.; Takacs, L.; Liu, H.C.; Gu, W.; Sienkiewicz, M.; Koster, R. D.; Gelaro, R.; Stajner, I.; Nielsen., J. E. The GEOS-5 Data Assimilation System-Documentation of Versions 5.0.1, 5.1.0, and 5.2.0.; NASA: Washington, DC, December 2008, 2007; p 118.

20. Archer, C. L.; Jacobson, M. Z., Evaluation of global wind power. J. Geophys. Res. 2005, 110, (D12), D12110.

21. GE 3.6 MW Wind Turbine Technical Specifications.

http://www.gepower.com/prod_serv/products/wind_turbines/en/36mw/36mw_specs.htm (August 5),

22. Wang, X.; Wang, X.; Bie, C.; Mao, Y., The Reliability Index Study on Generation System in China Electric Power 1999, 32, (2), 24-28.

23. Archer, C. L.; Jacobson, M. Z., Supplying Baseload Power and Reducing Transmission Requirements by Interconnecting Wind Farms. J. Appl. Meteor. Climatol. 2007, 46, (11), 1701-1717.

24. EPRMC General report on power reliability for the first half years of 2010, 2011 and $2012 \mathrm{http}: / / \mathrm{www}$.chinaer.org/info.aspx?n=20120926145325967732 (January 20), 25. Giebel, G., Wind power has a capacity credit. A catalogue of 50+ supporting studies. e-WINDENG J. 2005, vp.

26. Zhang, N.; Kang, C.; Kirschen, D. S.; Xia, Q., Rigorous model for evaluating wind power capacity credit. let Renewable Power Generation 2013, 7, (5), 504-513.

27. U.S. EIA Updated Capital Cost Estimates for Utility Scale Electricity Generating Plants; U.S. Energy Information Administration: Washington, DC, April, 2013; p 201. 28. SERC A Briefing of the Costs for Electric Power Projects Constructed in 2007 and 2008; China's State Electricity Regulatory Commission: Beijing, December, 2009; p 87.

29. Electric Power Statistical Year Book Editorial Board, Electric Power Statistical Year Book 2012. China Electric Power Press: Beijing, 2013; p 818. 
572 30. Liu, M.; Wang, H.; Oda, T.; Zhao, Y.; Yang, X.; Zang, R.; Zang, B.; Bi, J.; Chen, 573 J., Refined estimate of China's CO2 emissions in spatiotemporal distributions.

574 Atmospheric Chemistry and Physics 2013, 13, (21), 10873-10882.

575 31. China Coal Resource Weekly Average Coal Price at Qinhuangdao Port.

576 http://en.sxcoal.com/76/0/datalist.html (November 12),

577 32. Wang, F.; Zhang, S., Forcasting Long-Run Coal Price in China: Based on the

578 State Space Model. Statistics \& Information Forum 2011, 26, (8), 67-72.

579 33. $\quad$ WANG, Z.; SHI, J.; ZHAO, Y. Technology Roadmap: China Wind Energy

580 Development Roadmap 2050; International Energy Agency and Energy Research

581 Institute: Paris, France, 2011; p 56.

582 34. Musial, W.; Ram, B. Large-Scale Offshore Wind Power in the United States:

583 Assessment of Opportunites and Barriers; NREL/TP-500-40745; National Renewable

584 Energy Laboratory: Golden, CO, September, 2010; pp 108-128.

585 35. Chang, J.-H., The Chinese Monsoon. Geographical Review 1971, 61, (3), 370-

$586 \quad 395$

587 36. Hart, E. K.; Jacobson, M. Z., The carbon abatement potential of high penetration 588 intermittent renewables. Energy \& Environmental Science 2012, 5, (5), 6592-6601.

589 37. SERC Regulatory Report on Wind Power Integration in Some Critical Regions in

590 China; State Electricity Regulatory Commission: Beijing, May, 2012; p 111.

591 38. IPCC Special Report on Carbon Dioxide Capture and Storage; Intergovernmental

592 Panel on Climate Change: Geneva, Switzerland, 2005; p 431.

593 39. Li, J. From Strong to Smart: the Chinese Smart Grid and its relation with the

594 Globe; Asia Energy Platform: Hong Kong September, 2009, 2009; p 10.

595 40. BP BP Statistical Review of World Energy BP: Oct 4, 2013; p 48.

596 